\title{
Double-stranded RNA induces disproportionate expression of thymic stromal lymphopoietin versus interferon- $\beta$ in bronchial epithelial cells from donors with asthma
}

\author{
Lena Uller, Marina Leino, Nicole Bedke, David Sammut, Ben Green, Laurie Lau, \\ Peter H Howarth, Stephen T Holgate, Donna E Davies
}

\begin{abstract}
- Supplementary figures and material are published online only. To view these files please visit the journal online (http:// thorax.bmj.com).
\end{abstract}

The Brooke Laboratories, Division of Infection, Inflammation and Repair, School of Medicine, University of Southampton, Southampton, UK

\section{Correspondence to \\ Lena Uller, The Brooke Laboratories, Mailpoint 810, Level F, Sir Henry Wellcome Laboratories, South Block, Southampton General Hospital, Southampton S016 6YD, UK; lena.uller@med.lu.se}

Received 25 August 2009 Accepted 30 April 2010

\section{ABSTRACT \\ Background Thymic stromal lymphopoietin (TSLP) is an epithelial cell-derived cytokine that strongly activates dendritic cells and can initiate allergic inflammation. Since exposure to rhinovirus or double-stranded (ds) RNA (a surrogate of viral infection) induces TSLP expression in bronchial epithelial cells (BECs), this cytokine may link innate antiviral responses and the type 2 adaptive immune response.}

Objective As BECs from donors with asthma have a deficient interferon (IFN) response to rhinovirus infection, a study was undertaken to test the hypothesis that their antiviral response shows a bias towards TSLP production.

Methods Primary BECs were grown from subjects with asthma and healthy volunteers. After exposure to dsRNA, interleukin (IL)-8, IFN $\beta$ and TSLP mRNA and protein expression were measured by RT-qPCR and ELISA, respectively.

Results dsRNA dose-dependently increased IL-8 expression in BECs with no significant difference between the groups. However, BECs from subjects with asthma expressed less IFN $\beta$ and more TSLP mRNA and protein in response to dsRNA than BECs from those without asthma (median (IOR) 57 (38-82) pg/ml vs 106 $(57-214) \mathrm{pg} / \mathrm{ml}$ for IFN $\beta(\mathrm{p}<0.05)$ and 114 $(86-143) \mathrm{pg} / \mathrm{ml}$ vs $65(32-119) \mathrm{pg} / \mathrm{ml}$ for TSLP $(p<0.05)$ in response to $10 \mu \mathrm{g} / \mathrm{ml}$ dsRNA for $24 \mathrm{~h})$. Induction of TSLP mRNA by dsRNA was blocked by Toll-like receptor 3 or protein kinase inhibitors or by preventing de novo protein synthesis, but not by neutralisation of type I IFN receptors.

Conclusion BECs from subjects with asthma are biased towards higher TSLP and lower IFN $\beta$ production in response to dsRNA, suggesting that viral infection in asthma may lead to an altered mediator profile that biases towards a Th2 immune response.

\section{INTRODUCTION}

Exacerbations of asthma constitute a major proportion of asthma morbidity and mortality ${ }^{1}$ and account for significant healthcare costs, identifying an important unmet need. It is now evident that asthma deterioration and exacerbations in children and adults are frequently associated with rhinovirus (RV) infection, ${ }^{2} 3$ and that the bronchial epithelium is the target for the virus. ${ }^{4}{ }^{5}$ Furthermore, infants who develop severe viral respiratory infections are more likely to develop asthma later in childhood, ${ }^{6}$ suggesting a potential link between infection and disease pathogenesis.

It has been shown that RV-exposed primary bronchial epithelial cells (BECs) from individuals with asthma have reduced innate antiviral responses and are more permissive for viral replication than cells from healthy controls. ${ }^{7}$ The antiviral response of BECs from subjects with asthma involved reduced generation of the type I and III interferons IFN $\beta^{7}$ and IFN $\lambda,{ }^{8}$ respectively. This deficient innate immune defence against RV infection is probably of pathogenic importance in exacerbations of asthma. ${ }^{7}$ However, despite increased viral infection of BECs from subjects with asthma, RV-induced epithelial production of cytokines such as interleukin (IL)-6 and RANTES did not differ between subjects with asthma and healthy controls. $^{7-9}$

Recently, an IL-7-like cytokine, thymic stromal lymphopoietin (TSLP), has been put forward as a particularly important epithelium-derived mediator in asthma. ${ }^{10} 11$ TSLP is produced by several epithelial cell lines, keratinocytes ${ }^{12}$ and airway epithelium. ${ }^{13}$ The pathophysiology of human TSLP involves innate allergic immune responses with direct effects of TSLP on mast cells and on immature dendritic cells (DCs). ${ }^{14} 15$ TSLP-activated DCs initiate adaptive allergic immune responses by triggering differentiation of naïve $T$ cells into inflammatory Th2 cells that produce several traditional Th2 cytokines and also large amounts of tumour necrosis factor $\alpha$ (TNF $\alpha) .{ }^{10}{ }^{14-16}$ Importantly, Ying et al ${ }^{13} 17$ observed that bronchial epithelial expression of TSLP mRNA is increased in severe asthma.

Factors that may increase TSLP expression, including viral stimuli, have been examined in vitro using BECs from healthy human individuals. ${ }^{14} 1819$ However, to our knowledge, no specific information is available on generation of TSLP in BECs from subjects with asthma to support the possibility of involvement of this cytokine in viral infection-evoked exacerbations of asthma. During replication, single-stranded (ss) RNA viruses such as RV produce double-stranded (ds) RNA which is detected as a 'danger signal' by the innate immune system. Double-stranded RNA appears to be crucial for many of the biological activities of RV infections since non-replicative RV and/or ssRNA are poor stimuli for epithelial interferon and cytokine generation. ${ }^{7} 20$ Polyinosine-polycytidylic acid (poly $(\mathrm{I}: \mathrm{C})$ ) is a synthetic dsRNA that acts as 
a molecular pattern associated with viral infections and has been shown to mimic the effects of RV infection in terms of inflammatory regulatory molecules and unresponsiveness to glucocorticoids. ${ }^{21-23}$ Based on its utility as a surrogate of viral infection, we hypothesised that exposure of BECs from subjects with asthma to dsRNA would strongly induce TSLP expression in association with lower levels of IFN $\beta$ compared with BECs from normal subjects. We therefore investigated the expression of TSLP, IFN $\beta$ and IL- 8 in response to treatment of BECs obtained from subjects with and without asthma with dsRNA.

\section{METHODS}

\section{Subjects}

Two groups of subjects were recruited from the departmental database and asthma clinic. These were healthy subjects without asthma and a group of subjects with asthma ranging from mild intermittent to moderate/severe persistent disease characterised according to the Global Initiative for Asthma guidelines involving symptoms, pulmonary function and medication as described in the online supplement. Inclusion criteria were non-smokers or those with a history of $<5$ pack-years (no current smokers) and no upper respiratory tract infection within the last 2 months. Subjects not fulfilling these inclusion criteria and pregnant or lactating women were excluded.

\section{Fibreoptic bronchoscopy}

Epithelial brushings were obtained by bronchoscopy using a fibreoptic bronchoscope (FB-20D; Olympus, Tokyo, Japan) in accordance with standard published guidelines and bronchial brushings were obtained using a standard sterile single-sheathed nylon cytology brush (BC 9C-26101; Olympus), all as previously described and explained in more detail in the online supplement.

\section{Epithelial cultures}

Primary cultures were established by seeding bronchial brushings into collagen-coated tissue culture flasks containing $3 \mathrm{ml}$ serum-free hormonally-supplemented bronchial epithelium growth medium (BEGM; Clonetics, San Diego, California, USA), ${ }^{24}$ as described in detail in the online supplement. BECs were seeded into 12-well plates (Nunc, Life Technologies) and, when $80-90 \%$ confluent, they were stimulated with poly (I:C) (Invitrogen Ltd, Paisley, UK) at different doses and time points (see online supplement).

Inhibition of TSLP mRNA expression in bronchial epithelial cells The Toll-like receptor 3 (TLR3) inhibitor chloroquine (SigmaAldrich, Gillingham, UK), an imidazolo-oxindole inhibitor of dsRNA-activated protein kinase (PKR), or its negative control (5-chloro-3-(3,5-dichloro-4-hydroxybenzylidene)-1,3-dihydroindol-2-one) (both from Merck-Calbiochem, Nottingham, UK) were added to BEC cultures $2 \mathrm{~h}$ prior to stimulation with $1 \mu \mathrm{g} /$ $\mathrm{ml}$ dsRNA. Protein synthesis was blocked by preincubating the BECs with cycloheximide (Sigma-Aldrich) for $1 \mathrm{~h}$ before stimulation. A neutralising antibody for the type I IFN receptor (Interferonsource-PBL, Biomedical Laboratories, Piscataway, New Jersey, USA) and its negative control mouse IgG2a isotype control (eBioscience, Hatfield, UK) were added at a concentration of $12 \mu \mathrm{g} / \mathrm{ml}$ at the time of addition of dsRNA. BECs were stimulated for $3 \mathrm{~h}$ and processed for mRNA expression as described below.

\section{Cytokine measurement by ELISA}

Release of TSLP (R\&D Systems, Abingdon, UK), IL-8 (Biosource International, California, USA) and IFN $\beta$ (PBL-Interferonsource,
New Jersey, USA) into culture supernatants of BECs was measured at $24 \mathrm{~h}$ after stimulation with dsRNA using ELISA kits according to the manufacturers' instructions.

\section{Quantification of IL-8, IFN $\beta$ and TSLP gene expression using reverse transcription and quantitative PCR (RT-qPCR)}

Total RNA was extracted from primary BECs using TRIzol (Invitrogen, Carlsbad, California, USA) according to the manufacturer's instructions and treated with RNase-free DNase I (Ambion, Huntingdon, UK) to remove any contaminating genomic DNA. RT-qPCR was performed as described in the online supplement.

\section{Statistical analysis}

Statistical analysis was performed using the SPSS 14.0 software package for Windows (Chicago, Illinois, USA). With the exception of the studies using pharmacological inhibitors, all data are reported as median values with interquartile ranges and were analysed using non-parametric tests. Data within each group (asthma and healthy) were analysed using the Friedman test and the Wilcoxon test for two-paired samples was performed for each group. Statistical differences between asthma and healthy groups were determined using the Mann-Whitney $U$ test for unrelated samples. For the inhibition studies, the data were normalised relative to the dsRNA-treated BEC cultures and are given as mean $\pm \mathrm{SD}$; statistical comparisons were made using the Student $t$ test. A $p$ value $<0.05$ was considered significant.

\section{RESULTS}

\section{Clinical characterisation of subjects}

Twenty-six subjects participated in the study, 13 healthy individuals and 13 with asthma. The clinical characteristics of the subjects are shown in table 1 .

\section{Effects of dsRNA on IL-8 expression}

IL-8 is regarded as a cytokine important for the innate immune response and is a mediator of neutrophilic inflammation. ${ }^{20}$ Treatment of BECs with dsRNA dose-dependently increased IL-8 gene expression at 3 and $6 \mathrm{~h}$ after treatment and this was sustained at $24 \mathrm{~h}$ (figure $1 \mathrm{~A}$ and figure $\mathrm{E} 1$ in online supplement). Comparing IL-8 mRNA levels between the asthma and healthy groups, there was no significant difference in gene expression. Protein levels of IL-8 were detectable in the cell supernatants, but again there was no significant difference between BECs from healthy subjects and those with asthma (figure 1B).

\section{Innate immune response to dsRNA: induction of IFN $\beta$ expression}

Bronchial epithelial IFN $\beta$ mRNA expression was induced at 3, 6 and $24 \mathrm{~h}$ after stimulation with dsRNA. In both the healthy and

Table 1 Clinical characteristics of study subjects

\begin{tabular}{lll}
\hline & Healthy controls & Asthmatics \\
\hline Number & 13 & 13 \\
Sex (\% male) & 38 & 54 \\
Mean (range) age (years) & $25(19-40)$ & $34(21-55)$ \\
Atopy (\%) & 0 & 85 \\
Mean (range) FEV $1 \%$ predicted & $104(86-119)$ & $89(68-113)^{*}$ \\
Inhaled glucocorticoids & 0 & $7 \dagger$ \\
LABA & 0 & 4
\end{tabular}

${ }^{*} \mathrm{p}=0.02$ vs healthy controls

†Seven subjects with asthma received inhaled steroids. Mild asthmatics $(\mathrm{n}=3)$ : mean daily dose $470 \mu \mathrm{g} /$ day. Severe asthmatics $(n=4)$ : mean daily dose $2050 \mu \mathrm{g} /$ day (dose expressed as dose of beclomethasone dipropionate (BDP) $\mu \mathrm{g} /$ day).

$\mathrm{FEV}_{1}$, forced expiratory volume in $1 \mathrm{~s}$; LABA, long-acting $\beta$-agonists 
(A)

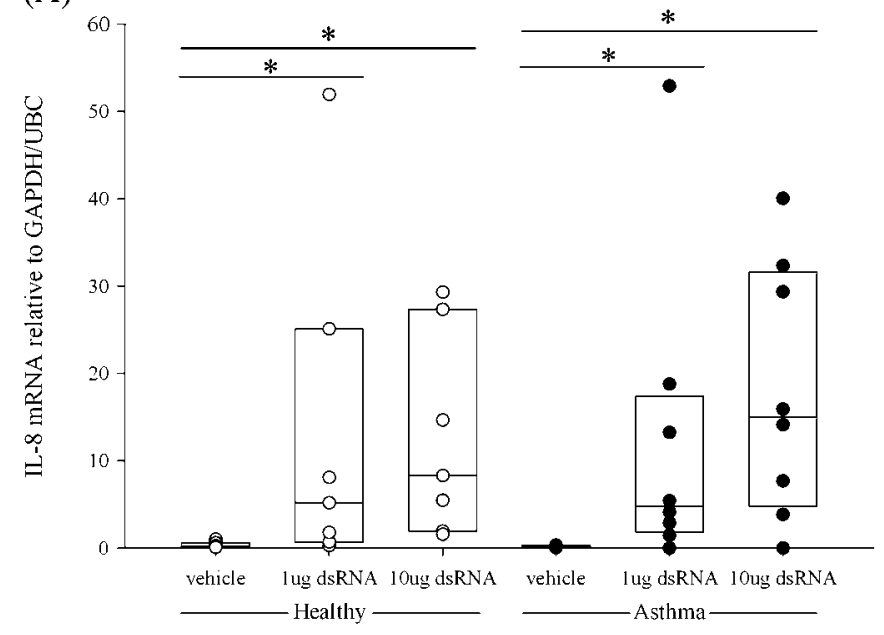

(B)

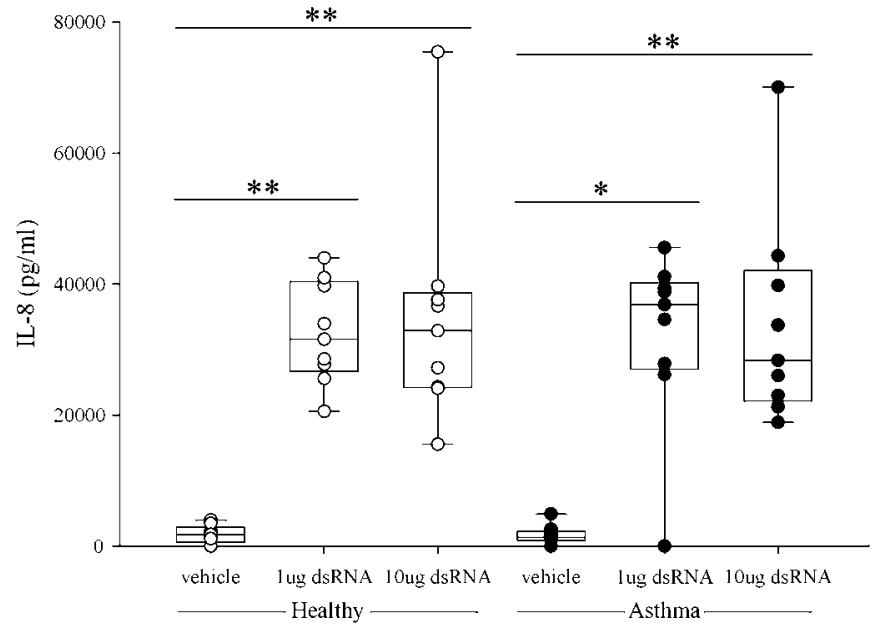

Figure 1 Induction of (A) interleukin (IL)-8 mRNA expression and (B) IL-8 protein expression in primary bronchial epithelial cells from healthy subjects (open circles) or subjects with asthma (closed circles) after stimulation with double-stranded RNA (dsRNA) at (A) $3 \mathrm{~h}$ and (B) $24 \mathrm{~h}$. The box plots show the median and interquartile range, and the bars show the 10th and 90th percentiles. ${ }^{*} p<0.05 ;{ }^{* *} p<0.01$ vs control untreated cells (Wilcoxon rank sum test).

asthma groups, dsRNA induced a dose-dependent increase in IFN $\beta$ mRNA which was maximal at $3 \mathrm{~h}$. However, the BECs from subjects with asthma expressed significantly lower levels of IFN $\beta$ mRNA than those from healthy controls $(1 \mu \mathrm{g}$ dsRNA, $\mathrm{p}<0.02 ; 10 \mu \mathrm{g}$ dsRNA, $\mathrm{p}<0.04$; figure $2 \mathrm{~A}$ ). At $24 \mathrm{~h}$, IFN $\beta$ gene expression was still significantly increased in the healthy group and was higher than in the asthmatic group $(p<0.02$; figure E2 in online supplement). The lower expression of IFN $\beta$ mRNA seen in response to dsRNA in BECs from subjects with asthma was confirmed at the protein level using ELISA. In both groups, a dose-dependent increase in IFN $\beta$ protein was observed, but IFN $\beta$ protein levels were significantly lower in the asthma group (figure $2 \mathrm{~B}$ ), as previously reported for RV infection. ${ }^{7}$

\section{Time course and dose response of dsRNA-induced TSLP expression in BECs}

Since TSLP has been reported to be rapidly induced in BECs after viral stimulation, we included two early $(3$ and $6 \mathrm{~h})$ and two later time points ( $24 \mathrm{~h}$ and $48 \mathrm{~h}$ ) for gene analysis with RT-qPCR and ELISA analysis for protein measurements. TSLP mRNA was

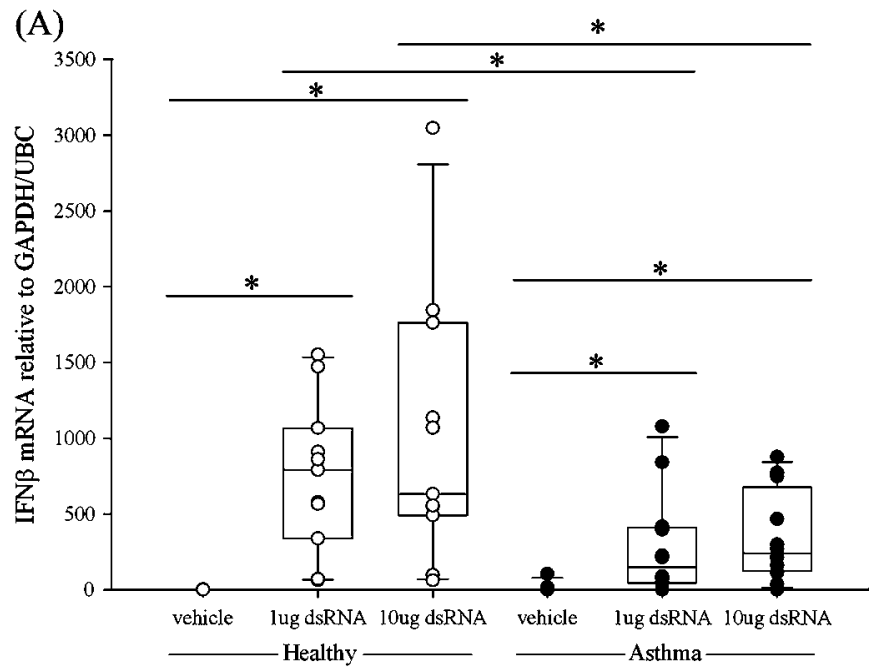

(B)

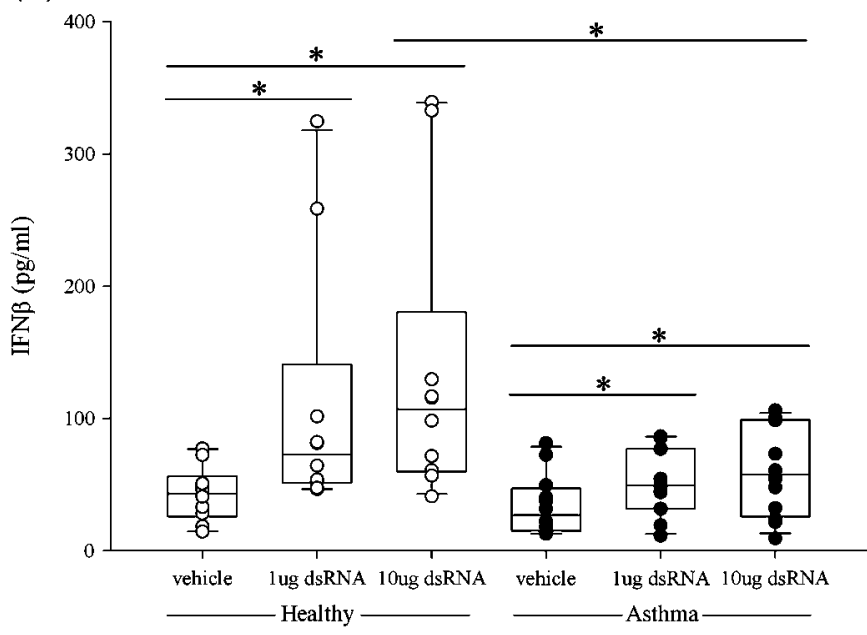

Figure 2 Induction of (A) interferon $\beta$ (IFN $\beta$ ) mRNA expression and (B) IFN $\beta$ protein release following treatment of bronchial epithelial cells from healthy subjects (open circles) or subjects with asthma (closed circles) after stimulation with double-stranded RNA (dsRNA) at (A) $3 \mathrm{~h}$ and (B) $24 \mathrm{~h}$. The box plots show the median and interquartile range, and the bars show the 10 th and 90th percentiles. ${ }^{*} p<0.05$ vs control untreated cells (Wilcoxon rank sum test). Between-group comparisons were made using the Mann-Whitney $U$ test.

dose-dependently induced at $3 \mathrm{~h}$ after stimulating the cells with dsRNA in both groups (figure $3 \mathrm{~A}$ ). At $6 \mathrm{~h}$ the asthma group maintained a significant and dose-dependent increase in TSLP mRNA while no significant $(p>0.05)$ TSLP mRNA was expressed in the healthy group (see figure E3 in online supplement). At both $3 \mathrm{~h}$ and $6 \mathrm{~h}$ after exposure to dsRNA, the highest dose of dsRNA $(10 \mu \mathrm{g} / \mathrm{ml})$ produced significantly higher levels of TSLP mRNA in BECs from subjects with asthma than in BECs from healthy controls $(p<0.05$ and $p<0.04)$. At the later time points, TSLP mRNA was no longer increased after dsRNA stimulation compared with baseline levels (see figure E4 in online supplement). Similarly, at $48 \mathrm{~h}$ no increase in TSLP mRNA was observed (data not shown). At $24 \mathrm{~h}$ after treatment, generation of TSLP protein by the BECs was dose-dependently increased by dsRNA in both the healthy and asthma groups (figure $3 \mathrm{~B}$ ). Similar to the gene expression data, significantly higher levels of TSLP protein were detected in the asthma group after $10 \mu \mathrm{g} / \mathrm{ml}$ dsRNA stimuli compared with healthy individuals $(p<0.04)$. 


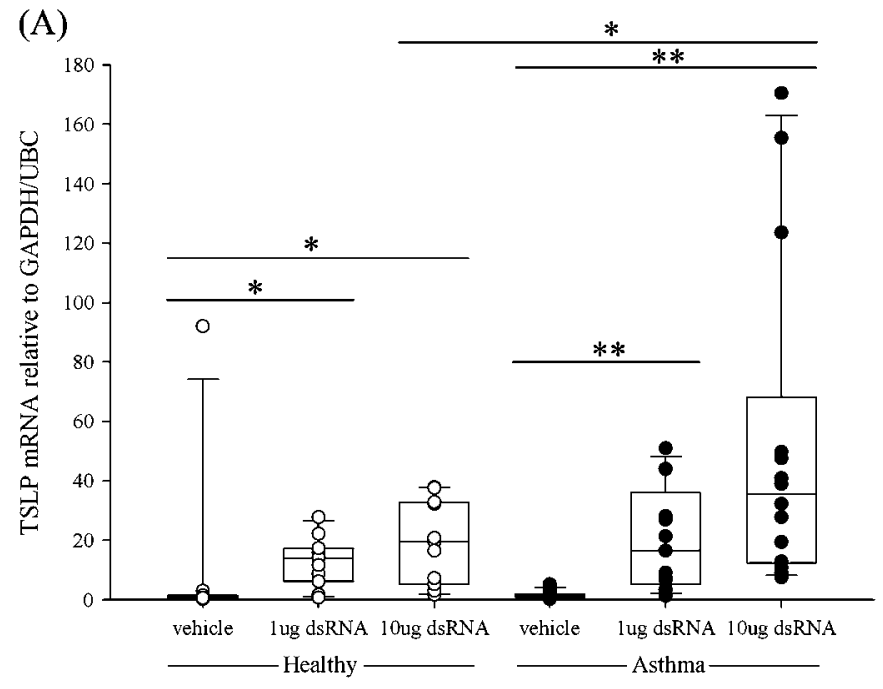

(B)

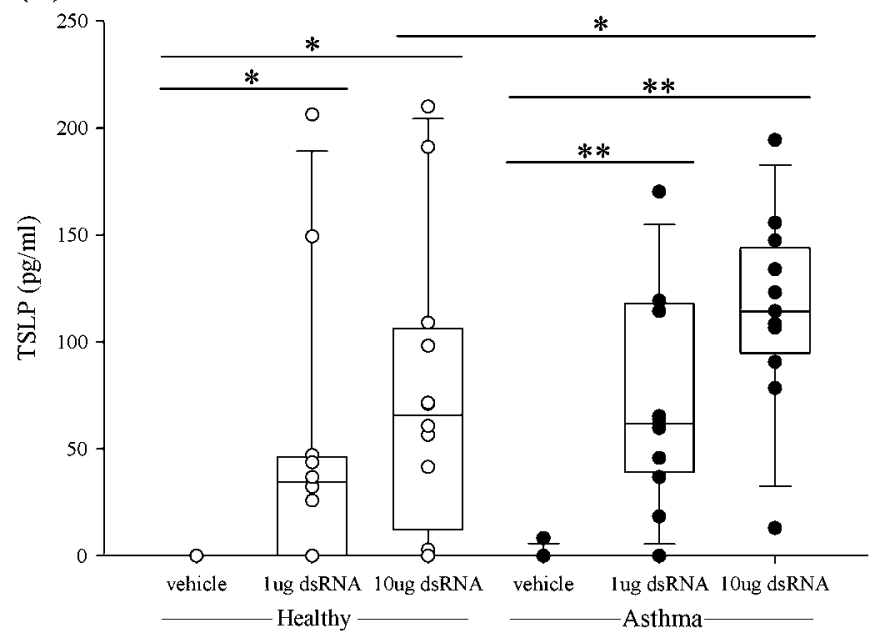

Figure 3 Induction of (A) thymic stromal lymphopoietin (TSLP) mRNA expression and (B) TSLP protein release in bronchial epithelial cells from healthy subjects (open circles) or subjects with asthma (closed circles) after stimulation with double-stranded RNA (dsRNA). The box plots show the median and interquartile range, and the bars show the 10th and 90th percentiles. ${ }^{*} p<0.05 ;{ }^{* *} p<0.01$ vs control untreated cells (Wilcoxon rank sum test). Between-group comparisons were made using the Mann-Whitney $U$ test.

\section{Effects of inhibitors of TLR3, PKR, protein synthesis and IFN $\alpha / \beta$ on dsRNA-induced TSLP mRNA}

To study the mechanisms involved in the induction of TSLP mRNA by dsRNA, several classes of pharmacological inhibitors were tested initially using BECs from healthy subjects. This showed that induction of TSLP mRNA was dose-dependently inhibited by the addition of chloroquine, which inhibits TLR3 by preventing acidification of the endosomes, ${ }^{25}$ and by a PKR inhibitor $(\mathrm{PKRi})^{26}$ (figure 4A, B). Similar results were obtained with BECs from subjects with asthma: TSLP mRNA was inhibited by $69.8 \pm 5.2 \%(\mathrm{n}=4)$ with chloroquine $(10 \mu \mathrm{g} / \mathrm{ml})$ and $93.5 \pm 5.0 \%(n=3)$ with PKRi $(1 \mu \mathrm{M})$. Neither chloroquine nor PKRi affected cell morphology (see figure E5 in online supplement), and neither inhibitor significantly reduced the induction of IL- 8 by combined treatment with TNF $\alpha$ and IL-4 (each at

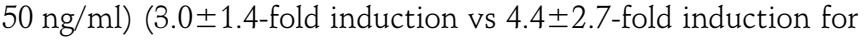
chloroquine $(10 \mu \mathrm{g} / \mathrm{ml})$ or $3.3 \pm 1.8$-fold induction for PKRi $(1 \mu \mathrm{M}))$. The specificity of the response was further demonstrated using the negative control compound for the PKRi, which had no significant inhibitory effect on TSLP expression. In addition, TSLP gene expression was found to be dependent on de novo protein synthesis as evidenced by inhibition using cycloheximide (figure 4C), but was not dependent on the autocrine or paracrine actions of type I IFNs released in response to exposure to dsRNA, as a neutralising antibody to the type I IFN receptor had no effect on TSLP mRNA expression (figure 4D). Cycloheximide did not inhibit induction of IL-8 by combined treatment with TNF $\alpha$ and IL-4.

\section{IFN $\beta / T S L P$ ratios}

As IFN $\beta$ can drive a Th1 response ${ }^{27}$ whereas TSLP favours Th2 responses, ${ }^{15}$ the reduced generation of IFN $\beta$ together with increased levels of TSLP in BECs from subjects with asthma in response to dsRNA made it of interest to calculate the ratio of IFN $\beta$ to TSLP on a per subject basis. At $3 \mathrm{~h}$ the mRNA ratio was significantly higher in the healthy group at both doses of dsRNA (figure 5A) (healthy vs asthma groups: median values 41 vs 14 $(\mathrm{p}<0.01)$ or 31 vs $11(\mathrm{p}<0.01)$ for 1 and $10 \mu \mathrm{g} / \mathrm{ml}$ dsRNA, respectively). At the protein level the ratios for IFN $\beta$ /TSLP were also significantly higher in the healthy group (figure $5 \mathrm{~B}$ ) (healthy vs asthma groups: median values 1.31 vs 0.50 or 0.96 vs 0.43 $(\mathrm{p}<0.007)$ for 1 and $10 \mu \mathrm{g} / \mathrm{ml} \mathrm{dsRNA}$, respectively).

\section{DISCUSSION}

Previous studies have shown that exposure to RV infection or dsRNA in vitro induces TSLP production in BECs from healthy subjects, ${ }^{14} 18$ suggesting that this cytokine may link the innate antiviral response and the type 2 adaptive immune response. As BECs from subjects with asthma have a deficient innate immune response to RV infection, ${ }^{7}$ we tested the hypothesis that expression of both IFN $\beta$ and TSLP is abnormal in asthmaderived BECs following stimulation with dsRNA. This hypothesis is strongly supported by our findings. In primary cultures of BECs obtained from 13 subjects with asthma and 13 healthy controls, dsRNA induced greater expression and release of TSLP in BECs from subjects with asthma than those obtained from healthy individuals. Our studies also showed a fundamental epithelial deficiency in generation of IFN $\beta$ in response to a generic TLR3 ligand in BECs from subjects with asthma. Our data therefore support and extend the earlier studies showing deficient IFN $\beta$ expression in response to RV infection. ${ }^{7}$ In contrast with our findings for TSLP and IFN $\beta$, there was no difference between BECs from healthy controls or subjects with asthma with regard to dsRNA-induced epithelial generation of IL-8. This observation agrees with previous studies of other inducers of IL-8 expression including RV, ${ }^{9}$ as well as house dust mite allergen, TNF $\alpha$ and IL-13. ${ }^{24}$

TSLP has been advanced as a key new cytokine with significant potential for initiating and aggravating asthma. ${ }^{13} 141719$ Ying and co-workers ${ }^{13}$ have observed that airway epithelial TSLP mRNA expression is increased in severe asthma. Although their patients were clinically free from respiratory infection, it cannot be excluded that a viral component could have contributed to the increased epithelial expression of TSLP in that study. The modest TSLP expression at baseline in the epithelium of subjects with asthma in our study is consistent with the findings of Ying et $a l^{13}$ who observed relatively little epithelial expression of TSLP in the bronchi of subjects with asthma with approximately the same degree of bronchial obstruction (percentage predicted forced expiratory volume in $1 \mathrm{~s}$ ) as that recorded in the subjects with asthma in our study. Our TSLP data further agree well with previous findings using commercially sourced epithelial cells. Thus, Kato et al ${ }^{18}$ reported viral 
Figure 4 Effect of inhibitors on the double-stranded RNA (dsRNA)-induced thymic stromal lymphopoietin (TSLP) response. Bronchial epithelial cells (BECs) were preincubated for $2 \mathrm{~h}$ with (A) chloroquine (Chlq) or (B) protein kinase inhibitor (PKRi) before stimulation with dsRNA. (C) Cycloheximide (CHX) was added $1 \mathrm{~h}$ before dsRNA and (D) type I interferon (IFN) receptor antibody ( $R A b$ ) was added at the same time as dsRNA. Cells were harvested at $3 \mathrm{~h}$ and TSLP gene expression was determined by RTqPCR. Data are presented as percentage stimulation in relation to TSLP mRNA expression for cells stimulated with dsRNA. The results are shown as mean \pm SEM from at least four independent experiments. ${ }^{*} \mathrm{p}<0.05$ vs dsRNA-treated cells (Wilcoxon signed rank test). In (D), data from BECs from healthy subjects and those with asthma are combined owing to the small numbers of BECs tested.
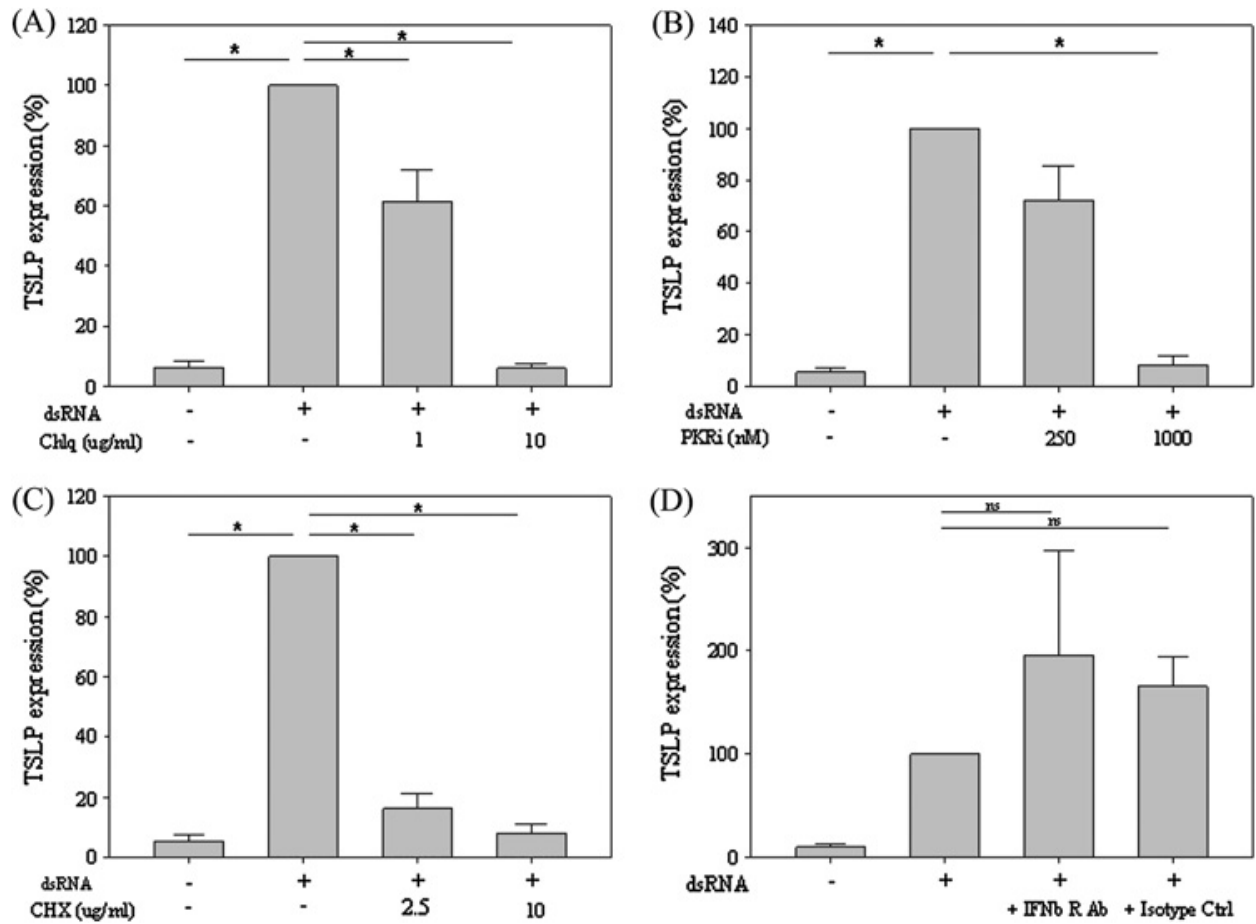

stimulus-induced expression and release of TSLP from normal BECs, and Allakhverdi et a ${ }^{14}$ reported dsRNA-induced release of TSLP from small airway epithelial cells. However, Lee and Ziegler, ${ }^{19}$ working with normal human BECs (sourced from Clonetics) observed no effect of $5 \mu \mathrm{g} / \mathrm{ml}$ dsRNA on TSLP mRNA expression $2 \mathrm{~h}$ after stimulation. This latter negative finding disagrees with the present study as well as with the findings of Kato et al, ${ }^{18}$ both of which studies demonstrated peak increases in TSLP mRNA $3 \mathrm{~h}$ after dsRNA stimulation. On the other hand, Kato et al ${ }^{18}$ did not observe any increase in TSLP mRNA even at $100 \mathrm{ng} / \mathrm{ml}$ TNF $\alpha$ whereas Lee and Ziegler ${ }^{19}$ demonstrated increased expression and production of TSLP in response to $10 \mathrm{ng} / \mathrm{ml}$ TNF $\alpha$.

Previous investigations of the mechanisms leading to induction of TSLP mRNA expression by dsRNA have shown the involvement of TLR3, nuclear factor kappa $B(N F \kappa B)$ and interferon regulatory factor 3 (IRF3) in this response. ${ }^{18}$ In agreement with these previous findings, the present study demonstrated inhibition of TSLP expression with chloroquine, suggesting the involvement of TLR3, while the observed inhibition of PKR, whose substrates include $I \kappa \mathrm{B}$, would limit activation of $N F \kappa B$. Although it is possible that these inhibitors had non-specific toxic effects, this is unlikely as the BECs showed no morphological evidence of toxicity and there was no effect of the inhibitors on TNFa/IL-4-induced IL-8 expression. Our data are consistent with the report by Gern et al ${ }^{20}$ which showed that the PKR inhibitor 2-aminopurine inhibited dsRNA-induced increases in other NFKB-regulated cytokines such as CCL5 and IL-8 in human BECs. Although Kato et al ${ }^{18}$ did not observe inhibition of dsRNA-induced TSLP expression in cells treated with siRNA against PKR, this may be due to insufficient knockdown of the PKR protein. As activation of PKR by dsRNA induces phosphorylation of the translation initiation factor EIF $2 \alpha^{28}$ leading to inhibition of the initiation of protein synthesis, our findings that TSLP expression is dependent on de novo protein synthesis also provides indirect support for the involvement of PKR. Since TLR3, IRF3 and NFKB are required for induction of both TSLP and IFN $\beta$ expression, the preferential induction of TSLP versus IFN $\beta$ in BECs from subjects with asthma is a conundrum. It seems unlikely that TSLP production is driven by autocrine release of IFN $\beta$ as neutralisation of the type I IFN receptor did not affect TSLP expression. In view of the requirement for de novo protein synthesis, it is possible that specific post-transcriptional events are key to understanding the differential regulation of TSLP and IFN $\beta$ expression. Further studies will be required to elucidate these mechanisms and to help explain the abnormal overproduction of TSLP and the underproduction of IFN $\beta$ in the epithelium of subjects with asthma.

The inability of BECs from subjects with asthma to mount a normal antiviral response to RV16 infection has been reported for the induction of both IFN $\beta^{7} 29$ and IFN $\lambda^{8}$, although two more recent studies failed to observe this difference. ${ }^{30}{ }^{31}$ In the study by Lopez-Souza et al, ${ }^{30}$ the absence of a disease-related difference may be explained by the fact that the BECs were differentiated at an air-liquid interface and were substantially more resistant to infection. Although Bochkov et al ${ }^{31}$ used undifferentiated BEC cultures similar to those used in the current study and the earlier studies of RV infection, ${ }^{7-9}$ they infected the cells using a minor group RV using a large innoculum (10 plaque forming units/cell). This led to substantial cytopathic cell death effects by $18 \mathrm{~h}$ of infection, and there was little evidence of an antiviral response which suggests that the BECs had died rapidly before an innate immune response could be mounted. In contrast, in the study by Wark et al, ${ }^{7}$ little cell death was evident, especially in the healthy control BEC cultures. A differential effect of viral titre on the antiviral response has been observed using West Nile virus, where the cells died rapidly by necrosis (evident at $8 \mathrm{~h}$ ) when infected with a multiplicity of infection $\geq 10$ whereas, at lower infectious doses, death was by apoptosis and occurred much more slowly (32 $\mathrm{h}$ after infection). ${ }^{32}$ In our current studies using synthetic dsRNA to activate TLR3, the innate antiviral response was not confounded by any significant cell death and we found lower IFN $\beta$ mRNA and protein expression in BECs from subjects with asthma. Furthermore, in the studies by Bochkov et a ${ }^{31}$ the BECs 


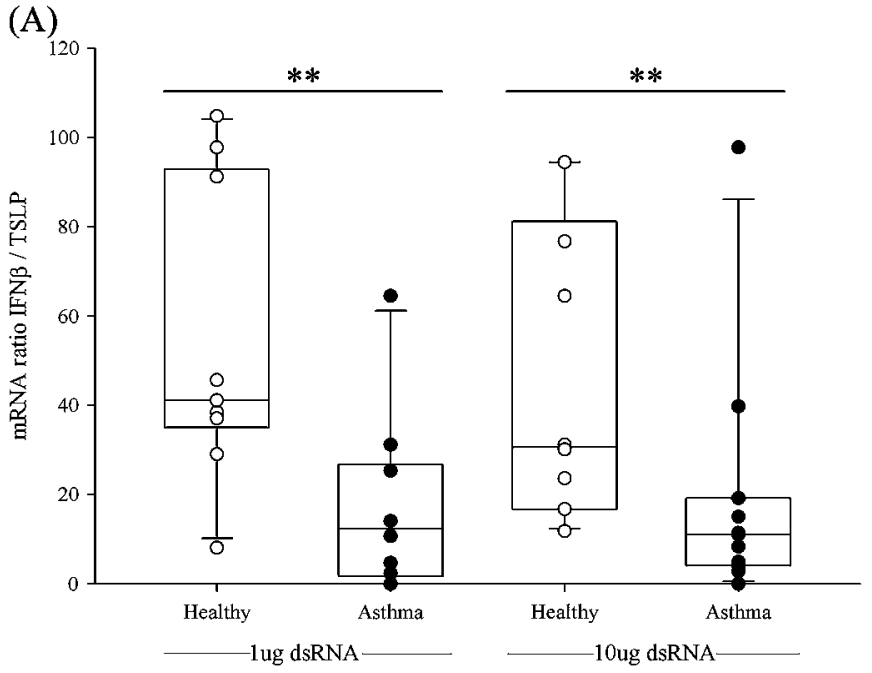

(B)

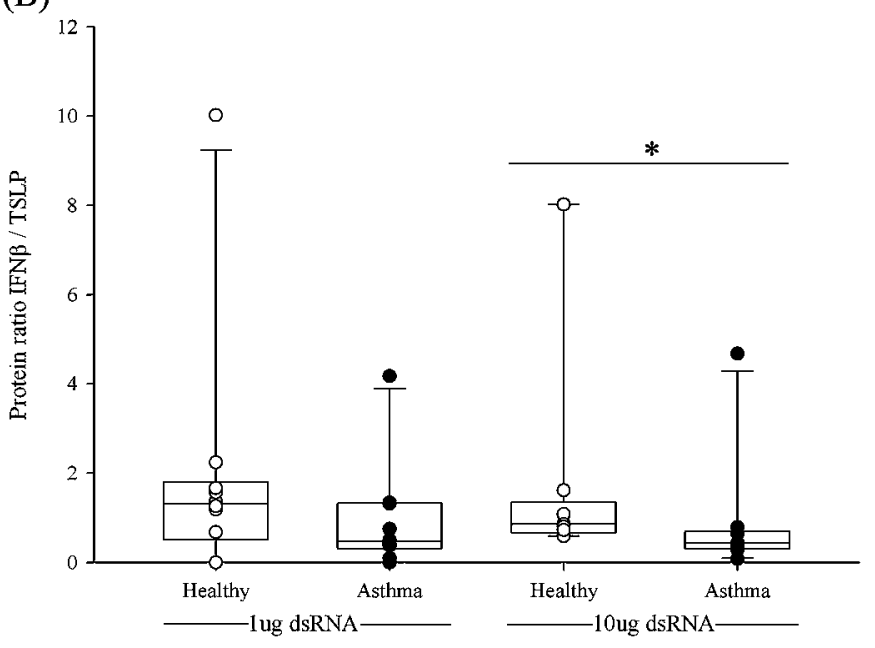

Figure 5 Expression of $(A)$ mRNA interferon $\beta /$ thymic stromal lymphopoietin (IFN $\beta / T S L P$ ) ratios or (B) protein IFN $\beta / T S L P$ ratios in bronchial epithelial cells from healthy subjects (open circles) or subjects with asthma (closed circles) in response to $1 \mu \mathrm{g} / \mathrm{ml}$ or $10 \mu \mathrm{g} / \mathrm{ml}$ doublestranded RNA (dsRNA) calculated on a per subject basis. ${ }^{*} \mathrm{p}<0.05$; ${ }^{* *} p<0.01$ vs control untreated cells (Wilcoxon rank sum test). Betweengroup comparisons of the ratios were made using the Mann-Whitney $U$ test.

were all from subjects with mild asthma whereas the initial study by Wark et al reported that BECs from corticosteroidtreated subjects with asthma were more permissive for RV replication than those from subjects with mild asthma. In the current study, seven of the 13 subjects with asthma were treated with corticosteroids and subgroup analysis suggested a trend for a lower dsRNA-induced IFN $\beta$ response in this group compared with the six donors whose asthma did not require corticosteroid treatment.

Recent studies suggest that IFN $\beta$ production by BECs is a key driver for normal DC maturation towards one capable of eliciting a protective Th1 immune response. ${ }^{33}$ In contrast, TSLPactivated DCs do not produce detectable proinflammatory cytokines but do produce high levels of TARC (CCL17) and MDC (CCL22) chemokines which preferentially attract CCR4expressing Th2 lymphocytes. ${ }^{10}$ These DCs also induce marked proliferation and expansion of allogeneic-naïve CD4 $+\mathrm{T}$ cells which produce large amounts of IL-13, IL- 5 and TNF $\alpha$ but only small amounts of IL-10 and IFN $\gamma .{ }^{10} 1634$ Stimulation of DC
TLR3 could generate a Th1 polarising signal (IL-12) but, in previous studies, dsRNA did not prevent TSLP-activated DCs from priming naïve CD4+ T cells to expand into inflammatory Th2 cells. ${ }^{34}$ Our observation that dsRNA-treated BECs from subjects with asthma show a deficiency in mobilising an antiviral host response (IFN $\beta$ ) in combination with overproduction of a potentially disease-initiating cytokine $\left(\right.$ TSLP) ${ }^{10} \quad 15 \quad 16$ underscores the potential role of an abnormal epithelium in response to early life virus infections leading to deviation of $\mathrm{T}$ cell maturation along a proallergic Th2 pathway.

Although increased epithelial TSLP expression has been observed in severe asthma, ${ }^{13} 17$ it is not known to what extent the present observations translate into in vivo airway epithelium in health and disease. One possible criticism is that the cells used in the present study were undifferentiated; however, this may reflect damaged and repairing epithelium which is readily apparent in asthma. ${ }^{35}$ Further studies of differentiated epithelial cell models may provide additional insight into the effect of differentiation status on TSLP expression and the persistence of disease-related differences in this context. In addition, although the observations in the present study were made using dsRNA as a mimic of danger responses of viral RNA, it will be important to extend these studies towards virus infection models and the consequence of epithelial infection on DC activation and T cell polarisation.

In conclusion, the use of dsRNA poly I:C as a stimulus has allowed us to demonstrate the reduced innate immune response of BECs from subjects with asthma independent of the severity of infection. As such, it provides a useful model for further exploratory studies. Our study shows a dual abnormality of BECs from subjects with asthma in response to dsRNA involving reduced generation of a major antiviral interferon (IFN $\beta$ ) and overproduction of a potentially disease-initiating cytokine (TSLP). The relationship between these two proteins in the epithelium of patients with asthma translates as an unfavourable ratio significantly different from that in the epithelium of those without asthma. These data support the possibility that intervention with TSLP inhibitory treatments and/or supplementary IFN $\beta$ administration to the bronchial mucosa may reduce the occurrence and severity of RV-induced exacerbations of asthma.

Funding Medical Research Council (MRC) UK, Swedish Medical Research Council, Swedish Heart-Lung Foundation and VINNOVA.

\section{Competing interests None}

Ethics approval Written informed consent was obtained from all volunteers before entering the study and all procedures were approved by the Southampton and South West Hampshire Research Ethics Committee (REC number 05/01702/165).

Provenance and peer review Not commissioned; externally peer reviewed.

\section{REFERENCES}

1. Holgate ST, Holloway J, Wilson S, et al. Understanding the pathophysiology of severe asthma to generate new therapeutic opportunities. J Allergy Clin Immunol 2006;117:496-506. quiz 507.

2. Nicholson KG, Kent J, Ireland DC. Respiratory viruses and exacerbations of asthma in adults. BMJ Clin Res Ed 1993;307:982-6.

3. Johnston SL, Pattemore PK, Sanderson G, et al. Community study of role of viral infections in exacerbations of asthma in 9-11 year old children. BMJ Clin Res Ed 1995:310:1225-9.

4. Gern JE, Galagan DM, Jarjour NN, et al. Detection of rhinovirus RNA in lower airway cells during experimentally induced infection. Am J Respir Crit Care Med 1997;155:1159-61.

5. Papadopoulos NG, Bates PJ, Bardin PG, et al. Rhinoviruses infect the lower airways. J Infect Dis 2000;181:1875-84.

6. Jartti T, Lee WM, Pappas $T$, et al. Serial viral infections in infants with recurrent respiratory illnesses. Eur Respir J 2008;32:314-20.

7. Wark PA, Johnston SL, Bucchieri F, et al. Asthmatic bronchial epithelial cells have a deficient innate immune response to infection with rhinovirus. J Exp Med 2005;201:937-47. 
8. Contoli M, Message SD, Laza-Stanca V, et al. Role of deficient type III interferonlambda production in asthma exacerbations. Nat Med 2006;12:1023-6.

9. Wark PA, Bucchieri F, Johnston SL, et al. IFN-gamma-induced protein 10 is a novel biomarker of rhinovirus-induced asthma exacerbations. J Allergy Clin Immunol 2007; 120:586-93.

10. Liu YJ. Thymic stromal lymphopoietin and OX40 ligand pathway in the initiation of dendritic cell-mediated allergic inflammation. J Allergy Clin Immunol 2007; 120:238-244.

11. Holgate ST. The epithelium takes centre stage in asthma and atopic dermatitis. Trends Immunol 2007;28:248-51.

12. Liu YJ. Thymic stromal lymphopoietin: master switch for allergic inflammation. $J$ Exp Med 2006:203:269-73.

13. Ying $\mathbf{S}, \mathbf{O}^{\prime}$ Connor B, Ratoff $\mathrm{J}$, et al. Thymic stromal lymphopoietin expression is increased in asthmatic airways and correlates with expression of Th2-attracting chemokines and disease severity. J Immunol 2005;174:8183-90.

14. Allakhverdi Z, Comeau MR, Jessup HK, et al. Thymic stromal lymphopoietin is released by human epithelial cells in response to microbes, trauma, or inflammation and potently activates mast cells. J Exp Med 2007;204:253-8.

15. Soumelis V, Reche PA, Kanzler $\mathrm{H}$, et al. Human epithelial cells trigger dendritic cell mediated allergic inflammation by producing TSLP. Nat Immunol 2002:3:673-80.

16. Wang J, Xing F. Human TSLP-educated DCs. Cell Mol Immunol 2008;5:99-106.

17. Ying S, O'Connor B, Ratoff J, et al. Expression and cellular provenance of thymic stromal lymphopoietin and chemokines in patients with severe asthma and chronic obstructive pulmonary disease. J Immunol 2008;181:2790-8.

18. Kato A, Favoreto S Jr, Avila PC, et al. TLR3- and Th2 cytokine-dependent production of thymic stromal lymphopoietin in human airway epithelial cells. J Immunol 2007;179:1080-7.

19. Lee HC, Ziegler SF. Inducible expression of the proallergic cytokine thymic stromal lymphopoietin in airway epithelial cells is controlled by NFkappaB. Proc Natl Acad Sci U S A 2007; 104:914-19.

20. Gern JE, French DA, Grindle KA, et al. Double-stranded RNA induces the synthesis of specific chemokines by bronchial epithelial cells. Am J Respir Cell Mol Biol 2003;28:731-7.

21. Heinecke L, Proud D, Sanders S, et al. Induction of B7-H1 and B7-DC expression on airway epithelial cells by the Toll-like receptor 3 agonist double-stranded RNA and human rhinovirus infection: in vivo and in vitro studies. J Allergy Clin Immunol 2008;121:1155-60.
22. Bengtson SH, Eddleston J, Christiansen SC, et al. Double-stranded RNA increases kinin $\mathrm{B} 1$ receptor expression and function in human airway epithelial cells. Int Immunopharmacol 2007;7:1880-7.

23. Konno S, Grindle KA, Lee WM, et al. Interferon-gamma enhances rhinovirus-induced RANTES secretion by airway epithelial cells. Am J Respir Cell Mol Biol 2002;26:594-601.

24. Lordan JL, Bucchieri F, Richter A, et al. Cooperative effects of Th2 cytokines and allergen on normal and asthmatic bronchial epithelial cells. J Immunol 2002:169:407-14.

25. de Bouteiller 0, Merck E, Hasan UA, et al. Recognition of double-stranded RNA by human toll-like receptor 3 and downstream receptor signaling requires multimerization and an acidic pH. J Biol Chem 2005;280:38133-45.

26. Jammi NV, Whitby LR, Beal PA. Small molecule inhibitors of the RNA-dependent protein kinase. Biochem Biophys Res Commun 2003;308:50-7.

27. Longhi MP, Trumpfheller C, Idoyaga J, et al. Dendritic cells require a systemic type interferon response to mature and induce CD4+ Th1 immunity with poly IC as adjuvant. J Exp Med 2009:206:1589-602.

28. Garcia MA, Meurs EF, Esteban M. The dsRNA protein kinase PKR: virus and cell control. Biochimie 2007;89:799-811.

29. Wark PA, Grissell T, Davies B, et al. Diversity in the bronchial epithelial cell response to infection with different rhinovirus strains. Respirology Carlton Vic 2009;14:180-6.

30. Lopez-Souza N, Favoreto S, Wong H, et al. In vitro susceptibility to rhinovirus infection is greater for bronchial than for nasal airway epithelial cells in human subjects. J Allergy Clin Immunol 2009;123:1384-90. e1382.

31. Bochkov YA, Hanson KM, Keles $S$, et al. Rhinovirus-induced modulation of gene expression in bronchial epithelial cells from subjects with asthma. Mucosal Immunol 2010;3:69-80

32. Chu JJ, Ng ML. The mechanism of cell death during West Nile virus infection is dependent on initial infectious dose. J Gen Virol 2003;84(Pt 12):3305-14.

33. Rate A, Upham JW, Bosco A, et al. Airway epithelial cells regulate the functional phenotype of locally differentiating dendritic cells: implications for the pathogenesis of infectious and allergic airway disease. J Immunol 2009;182:72-83.

34. Tanaka J, Watanabe N, Kido M, et al. Human TSLP and TLR3 ligands promote differentiation of Th17 cells with a central memory phenotype under Th2-polarizing conditions. Clin Exp Allergy 2009;39:89-100.

35. Puddicombe SM, Polosa R, Richter A, et al. Involvement of the epidermal growth factor receptor in epithelial repair in asthma. Faseb J 2000;14:1362-74. 